\title{
Stage IB Uterine Corpus Cancer AJCC v7
}

National Cancer Institute

\section{Source}

National Cancer Institute. Stage IB Uterine Corpus Cancer A/CC V7. NCI Thesaurus. Code C6302.

Stage IB includes: T1b, N0, M0. T1b: Tumor invades one-half or more of the myometrium. N0: No regional lymph node metastasis. M0: No distant metastasis. This staging applies to carcinomas and carcinosarcomas. (AJCC 7th ed.) 